\title{
A re-entry tachycardia triggered by the spontaneous interruption of an atrial tachycardia
}
Carmelo Buttà ${ }^{\mathrm{a}}$, Antonino Tuttolomondo ${ }^{\mathrm{b}}$, Domenico Di Raimondo ${ }^{\mathrm{a}}$, Lucia Giarrusso ${ }^{a}$, Giuseppe Miceli ${ }^{a}$, Francesco Cuttitta ${ }^{b}$, Donata La Rosa ${ }^{a}$, Giuseppe Licata ${ }^{\mathrm{b}}$ and Antonio Pinto ${ }^{\mathrm{a}}$

The common atrioventricular nodal re-entry tachycardia is the most common form of paroxysmal supraventricular tachycardia. It starts frequently with a supraventricular ectopic beat that, on finding the fast pathway in refractory period, travels in the slow pathway as to appear as a prolongation of the PR interval on the ECG. In this study, we show a singular case of a common atrioventricular nodal reentry tachycardia triggered by the spontaneous interruption of an atrial tachycardia.

J Cardiovasc Med 2013, 14:000-000

A 77-year-old patient, affected by heart failure, undergoes a 24-h Holter ECG monitoring for palpitations. The Holter ECG shows a sustained paroxysmal supraventricular tachycardia (SVT) (see Fig. 1). It starts with a premature atrial contraction followed by other five identical $\mathrm{P}$ waves with regular $\mathrm{PP}$ intervals at atrial rate of about 250 beats per minute. The RR intervals are irregular and the atrioventricular ratio is variable. The interval between the sixth and the seventh $\mathrm{P}$ wave of tachycardia is longer (PP interval $385 \mathrm{~ms}$ ) than previous
Keywords: atrial arrhythmias, cardiac anatomy, AVN re-entry, electrocardiography, Holter recorders

aU.O.C. Medicina Vascolare and ${ }^{b}$ U.O.C. Medicina Interna e Cardioangiologia, Dipartimento Biomedico di Medicina Interna e Specialistica, Università degli Studi di Palermo, Italy

Correspondence to Carmelo Buttà, MD, U.O.C. Medicina Vascolare, Dipartimento Biomedico di Medicina Interna e Specialistica, Università degli Studi di Palermo, Piazza delle Cliniche ${ }^{\circ} 2$ 2, 90127 Palermo, Italy Tel: +39 0916552150; fax: +39 0916552150; e-mail: carmelob147@tiscali.it

Received 21 January 2013 Revised 10 March 2013 Accepted 7 April 2013

PP intervals; hence PP and RR intervals become regular and atrioventricular ratio becomes $1: 1$ to the end of tachycardia.

It is plausible that not just one, but two mechanisms are involved in this paroxysmal SVT. The initial six $\mathrm{P}$ waves represent a short atrial flutter/tachycardia with variable atrioventricular conduction, but the following tachycardia is a re-entry tachycardia. Since $\mathrm{P}$ waves are negative on the inferior leads and RP interval is $70 \mathrm{~ms}$ (see Fig. 2), this

Fig. 1

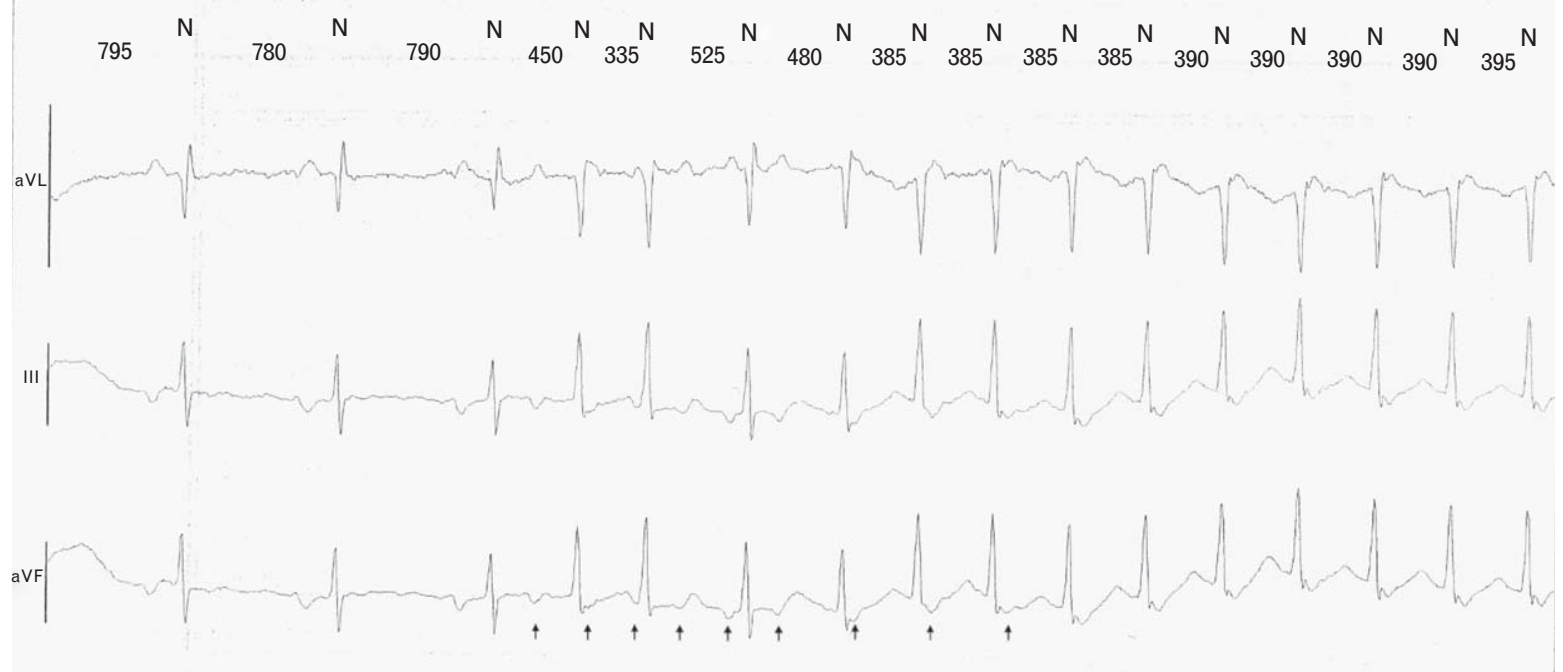

Beginning of paroxysmal supraventricular tachycardia. The indicators show the $\mathrm{P}$ waves (see text for discussion). 


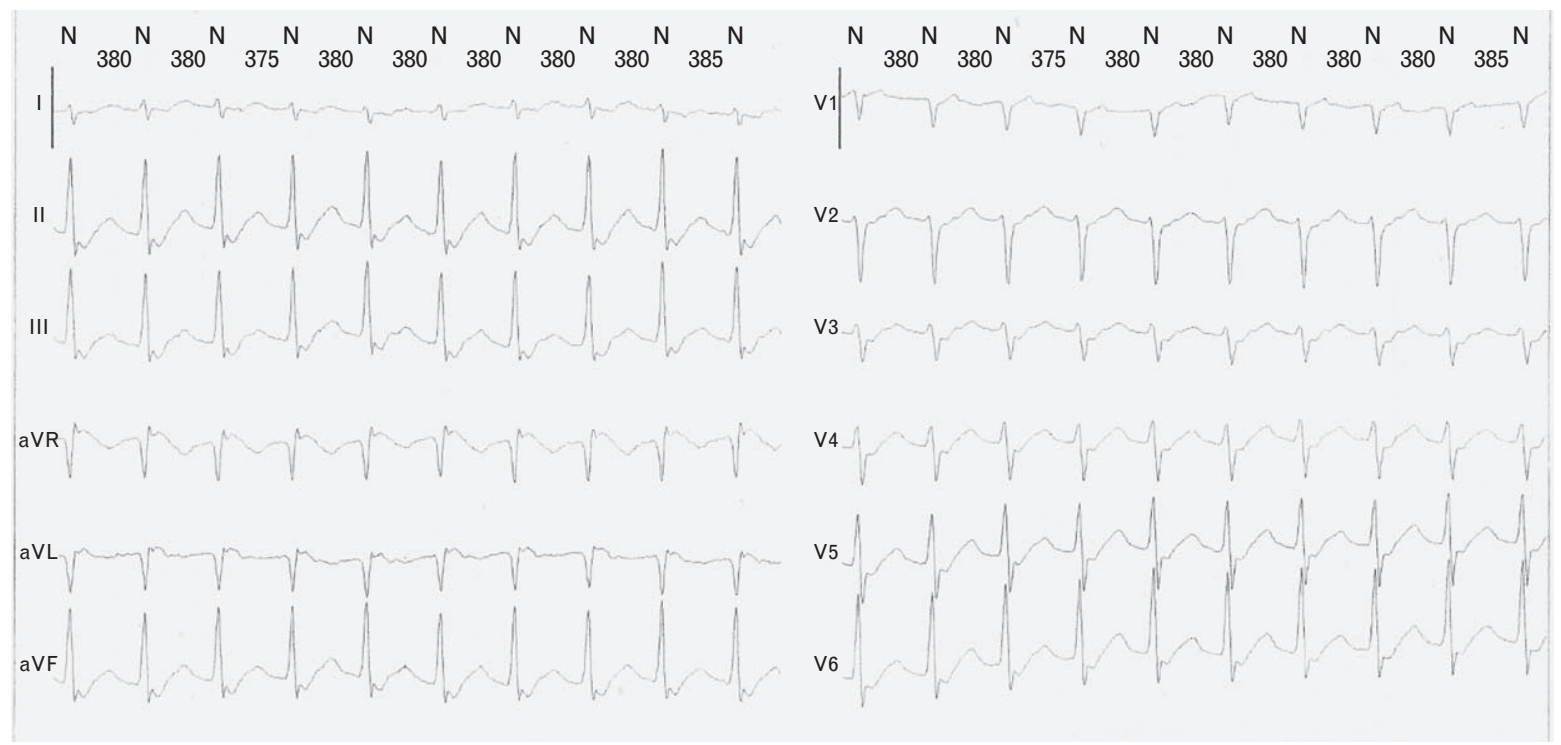

Re-entry tachycardia (see text for discussion).

second tachycardia seems to be a common atrioventricular nodal re-entry tachycardia (AVNRT). ${ }^{1}$

The common AVNRT is the most common form of paroxysmal SVT. ${ }^{1}$ It starts frequently with a supraventricular ectopic beat that, on finding the fast pathway in refractory period, travels in the slow pathway causing a prolongation of the PR interval on the ECG. ${ }^{2}$ In our case, when the atrial tachycardia stops, the atrial impulse seems to find the fast pathway in refractory period and so it reaches the ventricles through the slow pathway. Subsequently, when the fast pathway becomes excitable again, a retrograde conduction to the atria occurs through it; in this way, the AVNRT begins.

The PP interval between the sixth and the seventh $\mathrm{P}$ wave (that is the PP interval of beginning of the second tachycardia) has the same length of following PP intervals; this supports our diagnostic hypothesis. In fact, the length of a PP interval represents the whole conduction time of the nodal re-entry circuit, and it should remain constant from the beginning to the end of a common AVNRT, as well as the RR intervals.

The common AVNR'T is a paroxysmal SV'T that begins frequently with a supraventricular ectopic beat. In this study, we showed a singular case of a common AVNRT tachycardia triggered by the spontaneous interruption of an atrial tachycardia.

\section{References}

1 Blomström-Lundqvist C, Scheinman MM, Aliot EM, et al. ACC/AHA/ESC guidelines for the management of patients with supraventricular arrhythmias: executive summary. J Am Coll Cardiol 2003; 42:1493-1531.

2 Oreto G. I disordini del ritmo cardiaco. Torino: Centro Scientifico Editore; 1997. p. 61. 


\section{JCM}

Manuscript No. 201694
Journal of Cardiovascular Medicine (JCM)

Typeset by Thomson Digital

for Lippincott Williams \& Wilkins

Dear Author,

During the preparation of your manuscript for typesetting, some queries have arisen. These are listed below. Please check your typeset proof carefully and mark any corrections in the margin as neatly as possible or compile them as a separate list. This form should then be returned with your marked proof/list of corrections to the Production Editor.

\section{QUERIES: to be answered by AUTHOR/EDITOR}

\begin{tabular}{|c|c|c|}
\hline QUERY NO. & QUERY DETAILS & RESPONSE \\
\hline \multicolumn{2}{|c|}{ NO QUERY }
\end{tabular}

